\title{
Palliative Mustard operation for transposition of the great arteries: late results after $15-20$ years
}

\author{
Gül Sagin-Saylam, Jane Somerville
}

\begin{abstract}
Objective-To assess the clinical, functional state, and complications late (15-20 years) after palliative Mustard operation. Design-Examination and evaluation of all patients presenting in adolescence and adult life after palliative Mustard operation for transposition of the great arteries and pulmonary vascular disease.
\end{abstract}

Setting-Grown-up Congenital Heart Unit specialised in the care of adolescents and adults with congenital heart disease, designated as having "quaternary" status within a tertiary referral centre for cardiac diseases.

Patients and methods-Database searched for patients referred after palliative Mustard for classic transposition of the great arteries. Ten patients aged 18-31 (mean (SD) $25.9(5.2)$ ) years with a palliative Mustard operation performed at age 1·7-15 (mean (SD) $9(4 \cdot 6)$ ) years were fully evaluated by echocardiography, exercise testing, Holter monitoring, and magnetic resonance imaging or radionuclide ventriculography, or both 15-20 years later.

Results-One patient died aged 25 years with biventricular failure (ability index 3/4), haemoptysis, and atrial flutter, eight were well (ability index 2 ), and one disabled (ability index 3). Arterial oxygen saturation at rest was $\mathbf{8 5}-\mathbf{9 8 \%}$ (mean (SD) $93.8(4) \%$ ) decreasing to $59-87 \%$ (mean $77(9.5) \%$ after limited exercise. Symptomatic arrhythmias occurred in four patients, atrial flutter being the most common, and two had sinus node dysfunction. Significant tricuspid regurgitation occurred in four patients.

Conclusion-Patients with palliative Mustard operation have a low incidence of symptomatic ventricular dysfunction and despite exercise limitation by hypoxia, continue to live active, near normal lives until their thirties.

Grown-Up congenital Heart (GUCH) Unit, Royal Brompton Hospital, London G Sagin-Saylam J Somerville

Correspondence to: DrJ Somerville, Grown-Up Congenital Heart Unit Royal Brompton Hospital, Sydney Street, London SW3 6NP.

Accepted for publication 23 August 1995
(Heart 1996;75:72-77)

Keywords: palliative Mustard operation; late results after 15-20 years; transposition of the great arteries, congenital heart disease

The concept of palliative Mustard operation was introduced by Lindesmith et $a l^{1}$ in 1972 for the treatment of patients with transposition of the great arteries and raised pulmonary vas- cular resistance. This is an intra-atrial baffle repair which leaves or creates ${ }^{2}$ a ventricular septal defect and has been shown to give good symptomatic relief over 7-13 years. ${ }^{3-5}$ Knowledge about the state and fate in adults is sparse. This study reports the findings in all adults patients seen in the Grown-up Congenital Heart Unit during the past 6-23 (mean (SD) $11(5 \cdot 7)$ ) years, 15-20 years after palliative Mustard operation.

\section{Patients and methods}

The Grown-Up Congenital Heart Unit database, established in 1976, was searched for patients with complete transposition of the great arteries and a previous palliative Mustard operation referred to a Grown-Up Congenital Heart Unit (adolescents aged 12-19 years and adults) initially at the National Heart Hospital, subsequently in the Royal Brompton Hospital. There were 10 patients (seven women and three men) aged 18-31 (mean (SD) $25.9(5 \cdot 2)$ ) years operated on between 1973 and 1978 at the age of 1.7-15 (mean (SD) $9(4 \cdot 6)$ ) years.

Table 1 summarises the patients' data. A large ventricular septal defect was left open in eight patients and was created at operation in two. Nine patients had increased pulmonary vascular resistance or biopsy-proven pulmonary vascular disease, or both. Three of these patients (nos 3, 8, and 10) had had previous pulmonary artery banding, but pulmonary vascular resistance was thought to be too high to safely close the ventricular septal defect at the time of the Mustard procedure. Another patient with previous pulmonary artery banding (no. 1) had normal pulmonary artery pressure and had a palliative Mustard operation because of a small right ventricle and straddling tricuspid valve. ${ }^{46}$ Although this patient did not have increased pulmonary vascular resistance like the other nine and the rationale for leaving the ventricular septal defect open in this case was different, the patent was included in this series as he underwent a palliative Mustard procedure preserving the original principles of the operation. One patient (no. 2) had had previous repair of preductal coarctation of the aorta but the patent arterial duct was left open.

The nine surviving patients were assessed in 1993, 15-20 (mean (SD) 17 (2)) years after the operation. Protocol investigation was performed in the outpatient clinic where eight patients attended regularly; one (no. 9) was investigated in another clinic and data 
Table 1 Clinical data in 10 patients with transposition of the great arteries who underwent palliative Mustard operation

\begin{tabular}{|c|c|c|c|c|c|c|c|c|}
\hline \multirow{2}{*}{$\begin{array}{l}\text { Patient } \\
\text { no }\end{array}$} & \multirow{2}{*}{$\begin{array}{l}\text { Age in } \\
1993 \\
\text { (years) }\end{array}$} & \multirow{2}{*}{$\begin{array}{l}\text { Diagnosis and } \\
\text { associated } \\
\text { defects }\end{array}$} & \multirow{2}{*}{$\begin{array}{l}\text { Previous } \\
\text { operations }\end{array}$} & \multirow{2}{*}{$\begin{array}{l}\text { Age } \\
\text { (years) }\end{array}$} & \multirow{2}{*}{$\begin{array}{l}\text { Additional surgery at } \\
\text { palliative Mustard }\end{array}$} & \multirow{2}{*}{$\begin{array}{l}\text { Age at } \\
\text { palliative } \\
\text { Mustard }\end{array}$} & \multicolumn{2}{|c|}{ Postoperative PAP } \\
\hline & & & & & & & $m m \mathrm{Hg}^{*}$ & $\%$ systemic \\
\hline 1 & 28 & $\begin{array}{l}\text { TGA, VSD, } \\
\text { small RV, } \\
\text { straddling TV }\end{array}$ & PAB, atrial septectomy & $\begin{array}{l}23 / 365 \\
11 / 12\end{array}$ & DePAB & 11 & $24 / 12(18)$ & 25 \\
\hline 2 & 30 & $\begin{array}{l}\text { TGA, IVS, } \\
\text { preductal CoA, } \\
\text { PDA, JAA, } \\
\text { right aortic arch } \\
\text { kyphoscoliosis }\end{array}$ & CoA repair & 13 & Create VSD & 13 & $115 / 80(90)$ & 100 \\
\hline 3 & 29 & TGA, VSD & $\begin{array}{l}\text { Atrial septectomy, } \\
\text { PAB, } \\
\text { right B-T shunt }\end{array}$ & $\begin{array}{l}2 / 12 \\
2 / 12 \\
7\end{array}$ & & 10 & $95 / 50(70)$ & 100 \\
\hline $\begin{array}{l}4 \\
5\end{array}$ & $\begin{array}{l}30 \\
24\end{array}$ & TGA, VSD & Atrial septectomy & 7 & Create VSD & 15 & $\begin{array}{l}120 / 70(90) \\
85 / 50(60)\end{array}$ & 100 \\
\hline 6 & 31 & $\begin{array}{l}\text { TGA, VSD } \\
\text { Mild valvar PS } \\
\text { Dextrocardia, visceral and } \\
\text { atrial situs inversus, } \\
\text { kyphoscoliosis }\end{array}$ & Atrial septectomy & 7 & Pulmonary valvotomy & 13 & $70 / 30(45)$ & 60 \\
\hline 7 & 20 & TGA, VSD & $\begin{array}{l}\text { Balloon atrial } \\
\text { septostomy }\end{array}$ & $4 / 12$ & & 2 & $75 / 40(55)$ & 100 \\
\hline 8 & 28 & $\begin{array}{l}\text { TGA, VSD, } \\
\text { Kyphoscoliosis }\end{array}$ & Atrial septectomy, PAB & $\begin{array}{l}3 / 12 \\
1.5\end{array}$ & DePAB & 8 & $60 / 35(48)$ & 50 \\
\hline 9 & 18 & $\begin{array}{l}\text { TGA, VSD, } \\
\text { JAA }\end{array}$ & & & & $1 \cdot 7$ & $80 / 50(60)$ & 85 \\
\hline $\begin{array}{l}10 \\
\text { (Dead, 1990) }\end{array}$ & 25 & TGA, VSD & Atrial septectomy, PAB & 3 & DePAB & 10 & $100 / 58(70)$ & 100 \\
\hline
\end{tabular}

*Values in parentheses indicate mean pressures.

B-T, Blalock-Taussig; CoA, coarctation of the aorta; DePAB, debanding of the pulmonary artery; IVS, intact ventricular septum; JAA, juxtaposition of the atrial appendages; PAB, pulmonary artery banding; PAP, pulmonary artery pressure; PDA, patent ductus arteriosus; PS, pulmonary stenosis; RV, right ventricle; TGA complete transposition of the great arteries; TV, tricuspid valve; VSD, ventricular septal defect.

obtained. The records of one patient (no. 10) who died in 1990 were reviewed. The study protocol included clinical examination, chest radiography, electrocardiography, transthoracic echocardiography (10 patients), exercise testing using the modified Bruce protocol (nine patients), oxygen saturation measurements at rest and on exercise (nine patients), and $24 \mathrm{~h}$ ambulatory electrocardiography (seven patients). Functional state was designated by the Ability Index designed by Warnes and Somerville. ${ }^{7}$ All patients had postoperative cardiac catheterisation between 1979 and 1993, and radionuclide ventriculography or magnetic resonance imaging, or both, for the assessment of ventricular function ${ }^{8}$ between 1990 and 1993. Echocardiography was used to evaluate intracardiac anatomy, intra-atrial baffle, ventricular size, and contractions; atrioventricular valve regurgitation was graded by colour flow Doppler as mild, moderate, or severe according to the extension and width of the regurgitant jet into the atrial venous compartment. Right and left ventricular ejection fractions were measured by magnetic resonance imaging or first pass and equilibrium gated radionuclide ventriculography, or both (normal ejection fraction for right ventricle $>35 \%$, left ventricle $>45 \%$ ).

Statistical analysis was performed using the Student's $t$ test for paired data and Fisher's exact test to compare differences between groups. A $p$ value $<0.05$ was considered significant. Results are expressed as mean (SD).

\section{Results}

FUNCTIONAL STATE

Eight patients (ability index 2) currently lead active lives. One patient (no. 2) with severe kyphoscoliosis has been classified as ability index 3 for four years since the age of 26 and another (no. 10) who died aged 25 from chronic right heart failure was ability index $3 / 4$ for 3 years before death.

Improvement in symptoms and signs (failure to thrive, heart failure, dyspnoea, and cyanosis) occurred initially in all patients after palliative Mustard operation and was maintained for $13.4(4 \cdot 7)$ years until age $15-30$ (mean (SD) 22.4 (5)) years. Five patients (nos $1,3,4,5$, and 9) aged 18-30 years showed no deterioration in symptoms, exercise capacity, or Ability Indices during the period of observation to date. The remaining five patients (nos 2, 6-8, and 10) developed heart failure or increasing cyanosis, or both between the ages of 15 and 24 years (fig 1). Heart failure and progressive cyanosis developed in two patients (nos 2 and 10) four and twelve years after the operation with subsequent deterioration of exercise capacity and Ability Indices; both had pulmonary artery pressures at systemic level and developed recurrent haemoptyses and paroxysmal atrial flutter. Patient no. 10 died 15 years after the operation while awaiting heart lung transplantation. Patient no. 2 who is now aged 30 has the lowest exercise and functional capacity of the survivors, 17 years after the operation. Another patient (no. 8) developed paroxysmal atrial flutter nine years after palliative Mustard operation with subse-

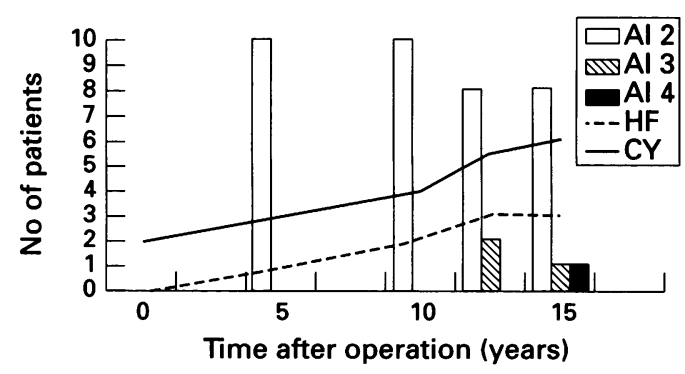

Figure 1 Development of heart failure (HF) and cyanosis (CY) with change in Ability Index (AI) in time after palliative Mustard operation. 
Table 2 Ability index, exercise performance, and systemic arterial oxygen saturations in 10 patients after palliative Mustard operation

\begin{tabular}{|c|c|c|c|c|c|c|c|c|c|c|}
\hline \multirow[b]{2}{*}{$\begin{array}{l}\text { Patient } \\
\text { no }\end{array}$} & \multirow[b]{2}{*}{$\begin{array}{l}\text { Age } \\
\text { (years) }\end{array}$} & \multirow[b]{2}{*}{$\begin{array}{l}\text { Ability } \\
\text { index }\end{array}$} & \multicolumn{2}{|c|}{ Exercise test } & \multicolumn{2}{|c|}{$\begin{array}{l}\text { Systemic arterial oxygen } \\
\text { saturation (\%) }\end{array}$} & \multicolumn{2}{|c|}{$\begin{array}{l}\text { Heart rate } \\
\text { (beats } / \text { min) }\end{array}$} & \multirow[b]{2}{*}{ At rest } & \multirow{2}{*}{$\begin{array}{l}\begin{array}{l}\text { Blood pressure } \\
(\mathrm{mm} \mathrm{Hg})\end{array} \\
\text { At peak exercise }\end{array}$} \\
\hline & & & Stage & $\begin{array}{l}\text { Total duration } \\
\text { (min and s) }\end{array}$ & At rest & At peak exercise & At rest & At peak exercise & & \\
\hline $\begin{array}{l}1 \\
2 \\
3 \\
4 \\
5 \\
6 \\
7 \\
8 \\
9\end{array}$ & $\begin{array}{l}28 \\
30 \\
29 \\
30 \\
24 \\
31 \\
20 \\
28 \\
18\end{array}$ & $\begin{array}{l}2 \\
3 \\
2 \\
2 \\
2 \\
2 \\
2 \\
2 \\
2\end{array}$ & $\begin{array}{l}3 \\
1 \\
4 \\
3 \\
4 \\
4 \\
4 \\
3\end{array}$ & $\begin{array}{rr}6 & 26 \\
1 & 52 \\
9 & 40 \\
7 & 16 \\
11 & \\
9 & 53 \\
9 & 10 \\
6 & 26\end{array}$ & $\begin{array}{l}97 \\
91 \\
96 \\
85 \\
98 \\
96 \\
94 \\
96 \\
91\end{array}$ & $\begin{array}{l}79 \\
72 \\
80 \\
59 \\
87 \\
76 \\
74 \\
86\end{array}$ & $\begin{array}{r}98 \\
101 \\
105 \\
74 \\
80 \\
89 \\
94 \\
73\end{array}$ & $\begin{array}{l}154 \\
136 \\
174 \\
149 \\
165 \\
156 \\
170 \\
150\end{array}$ & $\begin{array}{l}125 / 80 \\
110 / 70 \\
100 / 70 \\
90 / 60 \\
105 / 80 \\
120 / 80 \\
100 / 75 \\
125 / 85\end{array}$ & $\begin{array}{l}160 / 90 \\
120 / 70 \\
135 / 80 \\
105 / 65 \\
125 / 70 \\
155 / 80 \\
150 / 90 \\
180 / 80\end{array}$ \\
\hline 10 & 24 & $3 / 4$ & 2 & 430 & & & 99 & 150 & $120 / 80$ & $130 / 85$ \\
\hline
\end{tabular}

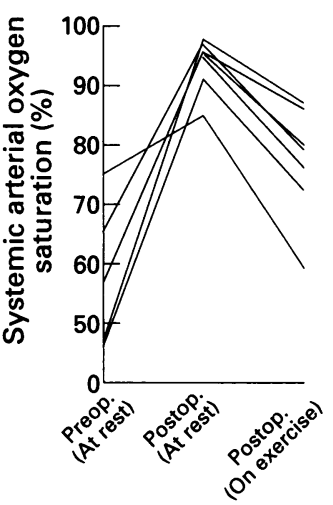
arterial oxygen saturations before (at rest) and 15-20 years after (at rest and on exercise) palliative

Mustard operation. Preop., preoperative; postop., postoperative.
Figure 2 Systemic

quent heart failure which was controlled by digoxin and diuretics; since then, the patient has experienced no further deterioration in symptoms or functional state and her ability index remains at 220 years after the procedure. Cyanosis in four patients, in two (nos 4 and 9) since the operation and apparent in two (nos 6 and 7) 10.5 and 14 years later, did not progress.

Table 2 summarises the Ability Indices and exercise performance with systemic arterial oxygen saturation. Four patients (nos 3, 5, 6, and 7) (Ability Index 2) reached stage 4 of the modified Bruce protocol with systemic arterial oxygen saturation at rest of $94-98 \%$, decreasing to $74-87 \%$ on exercise; three patients (nos 1 , 4 , and 8) (Ability Index 2) reached stage 3 with arterial oxygen saturation at rest of $85-97 \%$, decreasing to $59-86 \%$. Patient no. 2 (Ability Index 3) stopped at stage 1 with a decrease in arterial oxygen saturation from $91 \%$ to $72 \%$ and patient no. 10 with (Ability Index 3/4) stopped at stage 2. Exercise testing in these patients was carried out with caution, always supervised by a physician.

Four patients (nos 1, 3, 5, and 8) did not develop cyanosis at rest, four had mild (nos 4 , 6,7 , and 9), and two had moderate cyanosis (nos 2 and 10). The mean (SD) systemic arte-

Figure 3 Development of right ventricular $(R V)$ dysfunction, tricuspid regurgitation, and arrhythmia by age in patients after palliative Mustard operation. Regurg, regurgitation.

Figure 4 Development of right ventricular $(R V)$ dysfunction, tricuspid regurgitation, and arrhythmia in time after palliative Mustard operation. Regurg, regurgitation.
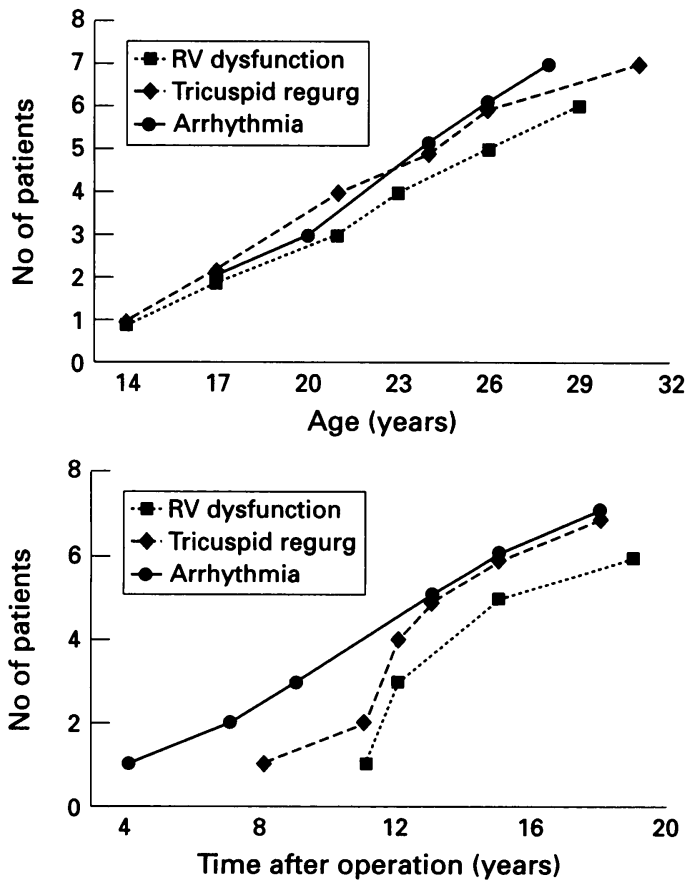

rial oxygen saturation increased significantly $(\mathrm{P}<0.001)$ from a preoperative value of 58.9 (12)\% (range $45-74 \%$ ) to 93.8 (4)\% (range $85-98 \%)$ at rest, decreasing to $77(9 \cdot 5) \%$ (range $59-87 \%$ ) on exercise, as measured 17 (2) years after the operation (fig 2). The mean (SD) haemoglobin concentration decreased from a preoperative value of 18.6 (3) (range $15 \cdot 5-23 \cdot 5) \mathrm{g} / \mathrm{dl}$ to $14.9(2 \cdot 7)$ (range $12-18 \cdot 7$ ) $\mathrm{g} / \mathrm{dl} 17$ (2) years after the operation; this difference was not statistically significant.

One patient (no. 8) with systemic arterial oxygen saturation of $96 \%$, pulmonary artery pressure $50 \%$ of systemic (60/35, mean 48 $\mathrm{mm} \mathrm{Hg}$ ), and pulmonary vascular resistance $75 \%$ of systemic ( $7 \mathrm{U} . \mathrm{m}^{2}$ ) had two uncomplicated pregnancies and two healthy children were delivered normally with combined management of obstetrician and cardiologist. This patient and two others (nos 5 and 6) with pulmonary artery pressures at systemic and $60 \%$ of systemic levels respectively had elective sterilization.

\section{PULMONARY ARTERY PRESSURE}

Table 1 shows the pulmonary artery pressure in patients aged 8-27.8 (mean (SD) $20 \cdot 2$ (6)) years measured $10(6 \cdot 3)$ years after palliative Mustard operation. The pulmonary artery pressure was normal (24/12, mean $18 \mathrm{~mm}$ $\mathrm{Hg}$ ) in one exceptional patient (no. 1) who had had pulmonary artery banding and underwent palliative Mustard operation because of small right ventricular size and straddling tricuspid valve. In the remaining nine patients, the pulmonary artery pressure was systemic in six (nos 2, 3, 4, 5, 7, and 10), two of whom developed haemoptysis, and $50-85 \%$ of systemic in three (nos 6, 8, and 9); the mean pulmonary artery pressure being 45-90 (mean (SD) 65.3 (16)) $\mathrm{mm} \mathrm{Hg}$ and the mean (SD) pulmonary vascular resistance 18.8 (12) U.m ${ }^{2}$. Two of the patients with previous pulmonary artery banding had systemic pulmonary artery pressures (nos 3 and 10) and in another (no. 8 ) the pulmonary artery pressure was $50 \%$ of systemic. There was no change in pulmonary artery pressure or pulmonary vascular resistance after palliative Mustard operation compared with preoperative values.

VENTRICULAR FUNCTION AND ATRIOVENTRICULAR VALVE REGURGITATION The right ventricular (systemic ventricle) ejection fractions ranged from $14 \%$ to $60 \%$ 
Table 3 Resting routine and 24 h ambulatory electrocardiogram (ECG) results in 10 patients after palliative Mustard operation

\begin{tabular}{|c|c|c|c|c|}
\hline Patient no & Ability index & Standard ECG & $\begin{array}{l}\text { Age at onset of } \\
\text { symptomatic arrhythmia } \\
\text { (years) }\end{array}$ & $24 \mathrm{~h}$ ambulatory $E C G$ \\
\hline 1 & 2 & 1 degree A-V block, VEs & & $\begin{array}{l}1 \text { degree A-V block, intermittent } \\
2 \text { degree A-V block with } 2: 1 \text { conduction, } \\
\text { multifocal VEs, SVE } \\
\text { couplets, } 1 \text { episode of VT }\end{array}$ \\
\hline 2 & 3 & $\begin{array}{l}\text { SR (paroxysmal atrial flutter), } \\
\text { RBBB }\end{array}$ & 17 & $\begin{array}{l}\text { SR, sinus bradycardia, frequent VEs } \\
\text { (isolated, couplets, bigeminy) }\end{array}$ \\
\hline 3 & 2 & SR, RBBB & & \\
\hline 4 & 2 & SR, RBBB & & $\begin{array}{l}\text { SR/occasional junctional, } \\
\text { sinus pauses }(2 \mathrm{~s})\end{array}$ \\
\hline 5 & 2 & SR, RBBB & & $\begin{array}{l}\text { SR, frequent VEs (isolated, couplets, } \\
\text { triplets, bigeminy) }\end{array}$ \\
\hline 6 & 2 & SR, frequent VEs & 19 & $\begin{array}{l}\text { SR, frequent VEs (couplets, bigeminy), } \\
\text { few SVEs }\end{array}$ \\
\hline $\begin{array}{l}7 \\
8\end{array}$ & $\begin{array}{l}2 \\
2\end{array}$ & $\begin{array}{l}\text { SR, RBBB } \\
\text { SR (paroxysmal atrial flutter) }\end{array}$ & 17 & $\begin{array}{l}\text { SR, multifocal VEs (isolated, couplets, } \\
\text { bigeminy), SVEs (isolated, couplets, } \\
\text { bigeminy) }\end{array}$ \\
\hline $\begin{array}{l}9 \\
10 \\
\text { (Dead) }\end{array}$ & $\begin{array}{l}2 \\
3 / 4\end{array}$ & $\begin{array}{l}\text { SR } \\
\text { Atrial flutter }\end{array}$ & 24 & Polymorphic VT \\
\hline
\end{tabular}

A-V, atrioventricular; RBBB, right bundle branch block; SR, sinus rhythm; SVEs, supraventricular extrasystoles; VEs, ventricular extrasystoles; VT, ventricular tachycardia.

(mean (SD) 40.4 (14)\%). Six patients (nos 1, $3,5,7,8$, and 10) developed impaired (< $35 \%)$ right ventricular ejection fractions by age $14 \cdot 5-29$ (mean (SD) $22(5 \cdot 3)$ ) years, 11-19 (mean 14.2(3)) years after palliative Mustard operation (figs 3 and 4 ) which was asymptomatic in five patients (ejection fractions $32-35 \%$ ) and associated with symptoms in one (no. 10) who died 3 years later from severe right (ejection fraction 14\%) and left (ejection fraction $38 \%$ ) ventricular dysfunction with severe tricuspid valve regurgitation. Four patients (nos 2, 4, 6, and 9) aged 18-31 (mean 27.3 (6)) years retain normal right ventricular function (ejection fractions $51-60 \%$ ).

The left ventricular (pulmonary ventricle) ejection fractions ranged from $38 \%$ to $62.5 \%$ (mean (SD) $52 \cdot 2(7) \%$ ). Among the nine survivors, none had impaired (ejection fraction < $45 \%$ ) left ventricular function.

Tricuspid regurgitation had developed in seven patients by the age of 14.5-31 (mean (SD) $22.4(5 \cdot 4)$ ), 8-18 (mean (SD) 13 (3)) years after the operation (figs 3 and 4 ) and was trivial in three (nos 1,7 , and 8), moderate in two (nos 4 and 5), and severe in two (nos 6 and 10 ), although only one was symptomatic. Tricuspid regurgitation was present in five of the six patients with impaired right ventricular ejection fraction. Two patients (nos 4 and 6) with moderate and severe tricuspid regurgitation, respectively, had good right ventricular function; tricuspid regurgitation had been present for 6 years and was not progressive in patient no. 4 (aged 30 years) while it was recently detected in patient no. 6 (aged 31 ). One (no. 3) of the four patients with previous pulmonary banding had mild mitral regurgitation not seen in the rest. None of the patients had obstruction in venoatrial pathways with magnetic resonance imaging or echocardiography.

\section{ARRHYTHMIAS}

Table 3 shows the current routine electrocardiogram and $24 \mathrm{~h}$ ambulatory electrocardiogram results. Four patients experienced symptoms from their arrhythmia; nos 2,8 , and 10 with atrial flutter and no. 6 with frequent ventricular extrasystoles. The basic rhythm is sinus in eight patients which is maintained throughout in four and associated with recurrent atrial flutter in two (nos 2 and 8); the basic rhythm was atrial flutter in patient no. 10 who died. Two patients had sinus node dysfunction according to previously defined surface electrocardiogram/Holter criteria ${ }^{9}$; no. 2 with sinus bradycardia ( 33 beats/min during sleep) and no. 4 with sinus pauses (2 s). Although only two patients had ventricular extrasystoles on resting standard electrocardiogram, Holter monitoring revealed ventricular extrasystoles in five patients, polymorphic ventricular tachycardia in one, and supraventricular extrasystoles in three. No arrhythmias were provoked by exercise.

\section{Discussion}

This series is selected by survival and therefore may not reflect the outcome of all patients undergoing palliative Mustard procedure. The size of the original cohort of patients having palliative Mustard operations is not known as they were operated on in several hospitals, most in The Hospital for Sick Children, Great Ormond Street where 41 patients had this operation between 1973 and 1980 with 38 hospital survivors. ${ }^{3}$

The mean follow up period of 15-20, mean (SD) 17 (2) years is the longest of published reports. ${ }^{3-5}$ Most patients in this series ( 8 of 10 ) maintained a good Ability Index (2) and were able to work with their lives minimally disturbed by cardiac problems despite the limitation of exercise tolerance from arterial desaturation with cyanosis on exertion.

The results of this study support the findings of others reporting improved exercise tolerance, a rise in arterial oxygen saturation, a decrease in polycythaemia after the procedure up to a mean of 10.5 years $^{3} 410$ and also confirm that improvement has been maintained until over 30 years in some. 
The major haemodynamic result of the redirection of pulmonary and systemic venous return is the net gain in systemic arterial oxygen saturation achieved by changing streaming and reducing the amount of systemic venous blood reaching the aorta while increasing the effective pulmonary blood flow. ${ }^{11}$ The situation becomes like Eisenmenger's syndrome with ventricular septal defect and it can be anticipated that the course will be similar with death from haemoptysis, right heart failure, cerebral incident, or sudden from unanticipated arrhythmia. ${ }^{12}$ Right heart failure which occurs in Eisenmenger's syndrome usually after 40-50 years may occur earlier after palliative Mustard operation as hypoxia is established earlier in infancy and in present in childhood. As yet, there is no evidence to confirm this and the left ventricular (pulmonary ventricle) ejection fractions of the nine survivors remain within normal limits, although frank failure has occurred in one.

There has been much concern about ventricular function after the Mustard operation in view of the differences in structure and contraction pattern of the right ventricle functioning as a systemic ventricle and the deleterious effects of preoperative hypoxia on the myocardium. ${ }^{13-15}$ Right ventricular and less pronounced left ventricular dysfunction have been reported in asymptomatic and symptomatic patients after the Mustard operation. ${ }^{131516}$ Although we found reduced right ventricular ejection fractions in six patients after palliative Mustard operation, it was mild and asymptomatic in five and severe with symptoms in only one (no. 10) who is now dead. It is interesting that progressive and symptomatic right ventricular dysfunction was not common, presumably because of the blow-off valve effect of the ventricular septal defect. The frequency of symptomatic right ventricular dysfunction (10\%) is less than that reported after ordinary Mustard procedure ${ }^{16}$ $(18 \%)$ in adult patients of similar age and follow up period, assessed by the same methods and criteria, but the difference is not statistically significant. Despite a high afterload due to increased pulmonary vascular resistance left ventricular function was well preserved in nine patients; and only one patient with previous pulmonary artery banding had mitral regurgitation which was mild and asymptomatic. Tricuspid regurgitation was common (seven of 10 patients; moderate in two and severe in two); this could be explained by the association of a large ventricular septal defect which distorted the anatomy. Tricuspid regurgitation was not associated with symptoms except in one patient (no. 10). Not all the patients with tricuspid regurgitation had right ventricular dysfunction (and vice versa), although they coexisted in five patients.

The seven patients who had serial Holter monitoring were found to have some form of arrhythmia, giving symptoms in four. Recurrent atrial flutter occurred in three patients and was associated with disabling symptoms. The frequency of symptomatic arrhythmia after palliative Mustard operation is similar to that reported after the Mustard procedure. ${ }^{16}$ The mechanism of arrhythmia after palliative Mustard operation should be similar to that of Mustard operation involving a diseased sinus node and interrupted atrial pathways, ${ }^{17}$ as the intra-atrial rerouting procedure is common to both operations. Sinus node dysfunction, the most common abnormality after the Mustard operation, ${ }^{161819}$ was less frequently detected in this series of patients with palliative Mustard (20\%) compared with that reported in patients who had the Mustard procedure $(59 \%)^{16}$ on Holter monitoring although the difference was not significant $(P=0.057)$. No patient had complete heart block, including those in whom a ventricular septal defect was created at operation. Only one patient had first and second degree atrioventricular block. Ventricular extrasystole complexes were common (five patients), giving symptoms in one. The only patient who presented with ventricular tachycardia had established ventricular failure which occurs similarly after Mustard operation and in other patients with chronic ventricular dysfunction and dilatation. In this series of patients after palliative Mustard operation, right ventricular dysfunction, tricuspid regurgitation, and arrhythmia developed by a mean (SD) age 22 (5) years, beginning around age 15 years and increasing in frequency thereafter until age 30 .

The results of this study show in a small, selected group of survivors beyond childhood that palliative Mustard operation provides good palliation in the long term, although there is exercise limitation from hypoxia. Because of Eisenmenger's physiology and the added problems of a right ventricle functioning as a systemic ventricle, arrhythmia following intra-atrial baffle repair, and hypoxia established early in infancy, patients are unlikely to survive much beyond the fifth decade. Earlier and more radical treatment has mostly prevented the development of pulmonary vascular disease in transposition of the great arteries so such cases rarely appear. If such patients present, however, the palliative Mustard procedure can be considered for those in whom pulmonary vascular disease has developed, ${ }^{20-22}$ albeit with a limited life span but a reasonable chance of 20-30 years of improved quality of life.

1 Lindesmith GG, Stiles QR, Tucker BL, Gallaher ME, Stanton RE, Meyer BW. The Mustard operation as a palliative procedure. $f$ Thorac Cardiovasc Surg 1972;63: $75-80$

2 Stark J, de Leval MR, Taylor JFN. Mustard operation and creation of ventricular septal defect in two patients with transposition of the great arteries, intact ventricular septum and pulmonary vascular disease. Am $¥$ Cardiol tum and pulm

3 Dhasmana JP, Stark J, de Leval M, Macartney FJ, Rees PG, Taylor JFN. Long-term results of the "palliative" Mustard operation . Am Coll Cardiol 1985;6:1138-41.

4 Humes RA, Driscoll DJ, Mair DD, Danielson GK, McGoon DC. Palliative transposition of venous return, long-term follow-up. $\mathcal{F}$ Thorac Cardiovasc Surg 1988;96:

5 Lindesmith GG, Stanton RE, Lurie PR, Takahashi M, Tucker BL, Stiles QR, et al. An assessment of Mustard's operation as a palliative procedure for transposition of the great vessels. Ann Thorac Surg 1975;19:514-20.

6 Dunn JM, Donner R, Black I, Balsara RK. Palliative repair of transposition of the great arteries with criss-cross 
heart: ventricular septal defect and hypoplastic right (systemic) ventricle. F Thorac Cardiovasc Surg 1982;83 755-60.

7 Warnes CA, Somerville J. Tricuspid atresia in adolescents and adults: current state and late complications. $\mathrm{Br}$ Heart F 1986;56:535-43.

8 Rees S, Somerville J, Warnes C, Underwood R, Firmin D, Klipstein $\mathbf{R}$, et al. Comparison of magnetic resonance imaging with echocardiography and radionuclide angiography in assessing cardiac function and anatomy following Mustard's operation for transposition of the great arteries. Am $\mathcal{F}$ Cardiol 1988;61:1316-22.

9 Kugler JD. Sinus node dysfunction. In: Garson A, Bricker JT, McNamara DG, eds. The science and practice of pediJT, McNamara DG, eds. The science and practice of pedi-
atric cardiology. Philadelphia: Lea and Febiger, 1990 . atric cardiolo.

10 Bernhard WF, Dick M II, Sloss LJ, Castaneda AR, Nadas AS. The palliative Mustard operation for double outlet right ventricle or transposition of the great arteries associated with ventricular septal defect, pulmonary arteria hypertension and pulmonary vascular obstructive disease, a report of eight patients. Circulation 1976;54 810-7.

11 Mair DD, Ritter DG, Danielson GK, Wallace RB McGoon DC. The palliative Mustard operation: rationale and results. Am $\mathcal{f}$ Cardiol 1976;37:762-8.

12 Wood P. The Eisenmenger syndrome, or pulmonary hypertension with reversed central shunt. $B M \mathcal{F}$ 1958;2:701-9, 755-62.

13 Hagler DJ, Ritter DG, Mair DD, Tajik AJ, Seward JB, Fulton RE, et al. Right and left ventricular function after the Mustard procedure in transposition of the great arteries. Am F Cardiol 1979;44:276-83.

14 Redington AN, Rigby ML, Oldershaw P, Gibson DG Shinebourne EA. Right ventricular function 10 years after the Mustard operation for transposition of the great arteries: analysis of size, shape and wall motion. Br Heart f 1989;62:455-61

15 Martin RP, Qureshi SA, Ettedgui JA, Baker EJ, O'Brien BJ, Deverall $\mathrm{PB}$, et al. An evaluation of right and left ventricular function after anatomical correction and intra-atrial repair operations for complete transposition of the great arteries. Circulation 1990;82: 808-16.

16 Warnes CA, Somerville J. Transposition of the great arteries: late results in adolescents and adults after the Mustard procedure. Br Heart $\mathcal{F}$ 1987;58:148-55.

17 Saalouke MG, Rios J, Perry LW, Shapiro SR, Scott LP. Electrophysiologic studies after Mustard's operation for d-transposition of the great vessels. Am f Cardiol 1978; d-transposition

18 Hayes CJ, Gersony WM. Arrhythmias after the Mustard operation for transposition of the great arteries: a longterm study. F Am Coll Cardiol 1986;7:133-7.

19 Gillette PG, El-Said GM, Sivarajan N, Mullins CE, Williams RL, McNamara DG. Electrophysiological abnormalities after Mustard's operation for transposition of the great arteries. Br Heart $\mathcal{F}$ 1974;36:1 186-91.

20 Ferencz C. Transposition of the great vessels, pathophysiologic considerations based upon a study of the lungs. Circulation 1966;33:232-41.

21 Newfeld EA, Paul MH, Muster AJ, Idriss FS. Pulmonary vascular disease in complete transposition of the great arteries: a study of 200 patients. $A m$ f Cardiol 1974:34: 75-82.

22 Haworth SG, Radley-Smith R, Yacoub M. Lung biopsy findings in transposition of the great arteries with ventricular septal defect: potentially reversible pulmonary vascular disease is not always synonymous with operability. $f$ Am Coll Cardiol 1987;9:327-33. 